\title{
Establishing and maintaining a low-cost zebrafish breeding and behavioral research facility
}

\author{
JOSEPH BILOTTA, SHANNON SASZIK, AMY S. DELORENZO, and HEATHER R. HARDESTY \\ Western Kentucky University, Bowling Green, Kentucky
}

\begin{abstract}
The purpose of this paper is to describe how to establish and maintain a low-cost zebrafish facility that can be used for both teaching and research purposes. The cost of the facility ranges from about $\$ 250$ to $\$ 1,000$, depending on the size of the facility and the experiments that will be conducted. The facility plan presented here also has the advantage that it can be disassembled so that it need not function year-round. A detailed list of supplies and materials is provided, along with detailed instructions on how to set up and maintain the adult and breeding portions of the facility. Finally, there is discussion of some of the general uses of a zebrafish facility, including a variety of procedures that are currently being used in behavioral research with this species.
\end{abstract}

An important part of the educational experience in psychology is the development of research skills. In fact, strong research skills are important for students who intend to pursue a doctoral degree in either experimental or clinical psychology (Keith-Spiegel, Tabachnick, \& Spiegel, 1994). In the past, work with animal subjects was a major research component of psychological science. However, this tradition has been in decline for a number of years. This trend is surprising, inasmuch as a recent survey reported that over $68 \%$ of the 1,188 students questioned believed that animal research was necessary for the progress of psychology (Plous, 1996). Unfortunately, despite our beliefs concerning what constitutes adequate training of our young scientists, our policies are dictated by the availability of resources. The main problem is the funding required to establish and maintain a research facility that involves animals. Other issues involve space, animal use requirements (including the training of personnel), and year-round maintenance. Although these factors may not pose a problem for large research universities, these factors can seem insurmountable for smaller institutions.

The purpose of this paper is to illustrate that the use of animals in research is not outside the realm of any educational facility. With a small budget and some ideas, an animal facility can be set up that can provide students with the opportunity to work with animals in a research setting. In fact, the impetus for this paper came from the number of requests our laboratory has had from individ-

This work was supported by Kentucky NSF/EPSCoR Grant 4-2885195-208 (to J.B.) and by a Western Kentucky University Faculty Research Grant (to J.B.). The authors thank Alan Hughes, Warren F. Patterson II, Carla Givin, William T. Dobis, and Leah Ann Fetsko for their helpful suggestions. Correspondence concerning this article should be addressed to J. Bilotta, Department of Psychology, Western Kentucky University, 1 Big Red Way, Bowling Green, KY 42101 (e-mail: joseph. bilotta@wku.edu). uals interested in setting up a similar facility at their institutions; these institutions range from universities to small colleges and high schools.

Recently, a common fish found in many pet stores has left its domesticated lifestyle and entered the world of science (Barinaga, 1990). The importance of the zebrafish (Danio rerio) to many fields of science-including genetics, biology, psychology, and neuroscience-is due to the fact that this vertebrate animal is able to reproduce prolifically and reach adulthood within 3 months. In addition, the zebrafish has transparent eggs, so its embryonic development can be examined without interfering with the process. Also, they are extremely hardy animals and require minimum space to house.

Because of the many advantages of using these animals, there has been an increase in the use of the zebrafish as an animal model (Laale, 1977). The consequence of this popularity is that there are a variety of resources available to those who use this model. For example, the University of Oregon has a large zebrafish facility and has published a book that details how to raise zebrafish as well as the many procedures used in zebrafish research (Westerfield, 1994). Unfortunately, most of these sources are designed for setting up a somewhat large facility, requiring substantial startup funds, space, and year-round maintenance. The present paper describes a low-cost zebrafish facility that anyone can assemble. The cost of the facility ranges from $\$ 250$ to $\$ 1,000$, depending on the experiments one wants to perform. (A price list is included in the Appendix.) This system has the advantage of being easy to set up and take down. It is feasible to use it only during the academic year. The system takes a couple of weeks to set up and be ready to begin breeding. When the experiments are finished, the tanks can be emptied and stored until the next year. Some of the ideas and procedures described here are original, and some have been obtained from other sources. However, the majority of the procedures obtained from other sources had to be modified for use on a much smaller scale. 


\section{METHOD}

\section{Subjects}

The subjects are zebrafish (Danio rerio). These are small tropical fish originating from the lakes of India (Mills, 1993). Adult zebrafish range in body length from 2 to $5 \mathrm{~cm}$ and can be purchased at a local pet store or from a hatchery. One advantage of buying them from a pet store is that you get them immediately. Also, you are able to pick the ones you want, avoiding unhealthy ones as well as buying only as many as you need. A disadvantage of buying them from a pet store is that you do not know the fish's history. For example, you do not know how they were raised, including the light:dark cycle, the type of food they were fed, and the age of the fish. When fish are purchased from a hatchery (e.g., Scientific Hatcheries, Huntington Beach, CA), the hatchery can provide you with details about the animal's history. If this information is important, a hatchery is the best way to obtain fish. The disadvantage of a hatchery is that there is typically a minimum order (e.g., 200 adults), which may exceed your system's capacity.

\section{Materials}

The Appendix contains a list of materials with approximate costs. Brand names are included, but comparable materials can be substituted. Most of the materials are standard aquarium supplies and, therefore, will not be described in detail. Purchasing a good how-to aquarium book (e.g., Mills, 1993) will explain the general details about setting up aquariums.

Tanks. Tanks come in different sizes: 5, 10,20, and 40 gal. are the most common and can be purchased at any pet or discount store. Tank size will be determined by the number of fish to be housed. About 10 adult fish can be housed in a 10-gal. tank with minimum maintenance. Two 10-gal. tanks will suffice for most purposes.

Tank racks. The biggest concern in choosing a tank rack is that it should be able to support the weight. A water-filled 10 -gal. tank weighs almost 100 pounds. To support the aquarium tanks, wooden shelves can be built. There are a number of sources that describe how to build an inexpensive, solid rack (e.g., Agbayani, 1995). The advantage of building a tank rack is that it can be designed precisely for your needs. For example, doors or curtains can be installed to create a light-controlled environment. Lights can be attached above the tank and set on a timer. However, if the racks enclose the tanks, make sure that there is some form of air circulation within the chamber. An alternative to building racks is to find a strong table.

\section{Animal Husbandry Procedures}

Tank set-up. The first procedure is to disinfect and clean the two 10-gal. tanks by placing about $3 \mathrm{in}$. of water in each tank with $65 \mathrm{ml}$ of chlorine bleach (Westerfield, 1994). With a sponge, wash down the tank sides with the disinfectant, cover the tanks with a piece of plastic or
Plexiglas, and let them sit overnight. Once they are disinfected, rinse the tanks well with water. Never use detergents or cleaning chemicals that are not specifically designed for aquarium use. Once the tanks have been rinsed, the next step is to fill the tanks with fish water. Water quality is crucial for breeding adult fish and their young. Zebrafish will not breed if the water conditions are not right. Tap water is generally not a good choice. It can contain a variety of chemical contaminants, and, unless you take the effort to determine the exact nature of your tap water, it can be dangerous to the fish. Also, it is possible that the water quality fluctuates (e.g., chlorine and mineral levels) over time. There are several ways to obtain appropriate tank water. One is to purchase distilled water; the other is to use a tap water deionizer for aquariums (see the Appendix). Whichever you decide to use, make sure that the final water is appropriate. The main requirements are that the water be soft (Mills, 1993) and have a $\mathrm{pH}$ of about 7.0 (Dobis \& Googe, 1996). Water hardness and $\mathrm{pH}$ test kits are available (see the Appendix). You will need to add aquarium salts (e.g., Instant Ocean $\mathrm{mix}$ ) to the water (about $2 / 3$ teaspoon per 10 gal. of water). Deionized and distilled water still may need some adjustment. For example, you may need to adjust the $\mathrm{pH}$ with a chemical $\mathrm{pH}$ adjuster.

Once you have the proper water in the tanks, water heaters and box filters should be placed into the tanks. An ideal temperature for both breeding and development of the embryos is $28.5^{\circ} \mathrm{C}$. A light:dark cycle also should be established, because zebrafish breeding depends on the light onset. A 14:10-h light-on:light-off cycle is the one used most commonly. Use this temperature and light:dark cycle in order to compare fish development with those from other laboratories (Westerfield, 1994).

The next step is to create a biological filter in the tank, which consists of bacteria that will break down fish waste products into harmless material. This filter will take several weeks to develop, but once it does, the filter can be maintained for some time. The process can be sped up by placing a few food flakes into the tank and/or by introducing a small fish into the tank after a week or so. As the biological filter develops, algae may form on the tank. Although this will not harm the fish, the tanks should be kept relatively clean by scrubbing the tank walls with a sponge.

Once the tanks are ready, it is time to add the fish. Initially, it will be difficult to determine their gender, because they are usually underfed by pet stores. Put the fish into one tank (this will be called the housing tank) and feed them as much as they will eat in $5 \mathrm{~min}$ about three times a day. At this point, feed the fish both flake food and live brine shrimp. This will provide a well-balanced high-protein diet and, after several days, the females will develop a "belly"; males stay thin no matter how much they eat.

Breeding. Zebrafish lay their eggs every morning following light onset; eggs are then eaten by the adults. To prevent this, a breeding net must be placed into the sec- 
ond tank (referred to as the breeding tank) the night before. The net is simply a $1 / 8$-in. mesh minnow net obtained from a sporting goods store. The net must be cut and shaped so that it lines the inside of the tank and should be no more than $1 \mathrm{in}$. above the floor. There are a number of ways to do this, such as building a wooden or Plexiglas frame (see, e.g., Schirone \& Gross, 1968). The goal is to line the tank so that the eggs fall through the net onto the tank bottom, which prevents the adults from eating the eggs. Remove the corner filter from the breeding tank, put it into the housing tank, and replace it with an air stone if there already is not one there.

When ready to breed, move the desired number of adults to the breeding tank. Feed the adults generously, but make sure that they are eating the food; do not let the food fall onto the tank bottom. This should be done before the lights go out on the night (or the afternoon) before breeding. The number of embryos is determined primarily by the number and gender ratio of the adults. For example, with six adults (three males and three females) expect to find about 150 fertilized eggs.

The adults will lay and fertilize the eggs when the lights go on the next morning; this is referred to as Day 0 or 0 days postfertilization (dpf). Give the adults at least 30 min after the lights go on to complete their task and then place the adults back into the housing tank. Once the adults have been removed, the net can be removed. To determine whether there are fertilized eggs, take a rigid, $1 / 4$-in.-diameter, plastic tube and siphon a small portion of water from the tank bottom. Place the water sample into a petri dish. If the dish is placed onto a piece of black paper or Plexiglas, the eggs can be seen. Fertilized eggs should appear clear, with a small round yolk floating inside the shell. If the egg appears cloudy or covered with white particles, it is not viable. These eggs are covered with fungus; this can be remedied for the next breeding session by adding methylene blue (see the Appendix). The fertilized eggs can be removed with a small eye dropper and placed into small storage containers, if you want to separate embryos into small groups; if not, they can be placed back into the tank.

Once the embryos have been counted and placed into the small storage containers, the containers can be floated in the heated tank to maintain their water temperature. The water level and temperature of both the tank and the containers must be maintained. If water needs to be added to the containers, add water from the tank and then add new water to the tank. Because the small containers are a closed water system, water quality can change rather quickly. Monitor the water often, particularly ammonia levels. To avoid a problem with ammonia levels, cut the sides of the containers and line the opening with a fine mesh aquarium filter bag. This will allow water to pass from the main tank into the small container without letting the eggs fall through. It is very important to monitor the ammonia level of this tank following breeding. With the adults spending the night and the eggs on the bottom of the tank, the biological filter may be disrupted. A $1 / 4$ water change following breeding will reduce the possibility of the ammonia level's rising.

Feeding the fry. During the first 3 days (i.e., $0-2 \mathrm{dpf}$ ), the embryos will feed off their yolks. They should begin to hatch at about $3 \mathrm{dpf}$. At this point, they will attach themselves to the walls or floor of the tank or the container. However, because there will be some fry who develop faster than others, they should be fed. At this age, they are too small for either flake food or brine shrimp. An excellent food source for the fry is a commercially available live paramecium solution (Liquifry). The solution comes in a tube and is very easy to use and store (rather than maintaining a stock of live paramecium). By 4-5 dpf, the fry will begin to swim around the tank.

Begin preparing live brine shrimp around $6 \mathrm{dpf}$ and feed the fry live brine shrimp along with the paramecium mixture at about $7 \mathrm{dpf}$. Over the next several days, the paramecium mixture should be decreased, and the amount of brine shrimp increased. By $9 \mathrm{dpf}$, if the fry are in the small containers, they should be placed into a larger one (about $1 \mathrm{l}$; Westerfield, 1994). At about $16 \mathrm{dpf}$, flake food can be used, if the flakes are ground into a fine powder. After 22 dpf, fish should be placed into the 10-gal. tank, if they are not there already.

Maintenance. Once the tanks are established, routine maintenance is required to keep the tanks in good condition. The best strategy is to do a little maintenance every few days, rather than once a month. This makes the environment more stable for the fish. While feeding the fish, make sure that there is enough water in the tanks to cover the heaters. Water evaporates over time and you will need to "top-off" the tanks with water. The most important job is to keep the tank free of debris and waste products. The corner filter will remove some of this, but it is best to vacuum the tanks every couple of days. A partial water change (about $1 / 3$ of the water) should be done every 3 to 4 weeks. When water is replaced, make sure that the aquarium salts are replaced accordingly. Once a month, check the filter material in the corner filter and replace it when necessary.

\section{GENERAL USES IN BEHAVIORAL RESEARCH}

The zebrafish facility described here can be used for a variety of purposes. It can be used to develop laboratory projects for a course or for individual student projects. It is very easy to develop small, yet interesting, projects that can be done by one or two students within a semester. Aside from student projects, high-caliber, publishable research can be conducted. There are a variety of response measures that can be used with zebrafish to conduct psychological studies. This section will describe briefly some of the response measures that are currently being used with zebrafish and how they might be used to conduct research across various areas in psychology, including sensation and perception, animal learning and behavior, psychopharmacology, and behavioral teratology. The 
projects described below are relatively inexpensive. For the most part, they require building and putting together equipment.

Many of the same techniques that are used in behavioral research with other fish, such as the goldfish (see Northmore, Volkmann, \& Yager, 1978), can be applied to zebrafish research. However, there are some exceptions. There are procedures that may work well with one fish species but, because of differences in temperament, may not work with others. For example, goldfish are relatively calm creatures and are suited to a variety of procedures, such as conditioned suppression procedures (see, e.g., Bilotta \& Powers, 1992), which require restraining the subject. The zebrafish, on the other hand, spends most of its time darting around the tank. Therefore, any type of restraining procedure will not work (Bilotta, personal observation). In addition, when testing different-sized zebrafish, the apparatus must be appropriate for the size of the fish. For example, in our laboratory it was found that the size of the chamber can influence the subject's response in motor activity and optomotor response procedures (see below).

\section{Physical Development}

Although these dependent measures are not necessarily behavioral in nature, they may be used in conjunction with behavioral measures to determine developmental deficits. These measures include body length, head and eye diameter, and so forth. An excellent reference for the staging of zebrafish embryos is The Zebrafish Book (Westerfield, 1994). Included are pictures of the various stages, with ages and a brief, written description of the important features of each stage.

The physical development measures can be used in psychopharmacology and behavioral teratology studies. For example, our laboratory has examined the effects of $\mathrm{pH}$ (Dobis \& Googe, 1996) and of the size of the rearing tank (Moore, Hardesty, Saszik, \& Bilotta, 1997) on development. In addition, we are currently using these measures in conjunction with behavioral measures to examine the effects of ethanol on prenatal development.

For simple demonstrations or measuring gross anatomical development, a stereoscope with a magnification ranging from $20 \times$ to $60 \times$ will suffice (see the Appendix). Viewing the embryos with a stereoscope while they are still in the egg (i.e., $0-3 \mathrm{dpf}$ ) is relatively easy to do, because they have transparent eggs and remain relatively stable in the viewing field. Once they have hatched and are capable of swimming, there are several ways to restrict their movement. One is to place them into a $.16-\mathrm{mg} / \mathrm{ml}$ solution of tricaine methanesulfonate (MS-222; Sigma, A5040) for about 2 min (the actual time will depend on fish size). Once they are anesthetized, remove them from the solution and place them into regular tank water. This will give you about $2 \mathrm{~min}$ of stable observation time.

\section{Locomotor Activity}

Several measures of motor activity have been used with zebrafish. One such measure is a hyperactivity measure in which the subject is placed into a small chamber with a grid on the chamber floor and the number of grid crossings recorded for a set period of time. Similar procedures for measuring motor activity have been used in larval fathead minnows (Ore, McElroy, \& Hoyt, 1997). Work in our laboratory with different-aged zebrafish has shown that comparable activity across age can be obtained by adjusting chamber size to match fish size. That is, when the fish length to chamber size ratio is held constant, the number of grid crossings are similar across age (C. Givin, personal communication, August 22, 1997). This response can be used in psychopharmacological and behavioral teratology research.

\section{Reflexive Behavior}

There are a number of reflexive behaviors that have been used in zebrafish research. The advantage of these behavioral measures is that they can be used immediately; that is, unlike operant behaviors, they require no acquisition time. For example, zebrafish are schooling fish, in that they tend to follow other fish. A number of studies have examined the relevant dimensions of the trigger stimulus for schooling behavior. For example, McCann, Koehn, and Kline (1971) displayed artificial fish of various sizes and body pattern (e.g., stripes versus no stripes) on the test tank wall, which was divided in half by a line drawn on the tank floor. They monitored the time the subject spent in each half of the tank, and they used this measure to determine which stimulus dimensions the zebrafish used to trigger schooling behavior.

Another swimming activity that can be used as a behavioral response measure is the optomotor response (Clark, 1981). Because zebrafish are schooling fish, they tend to follow moving patterns. The optomotor response takes advantage of this behavior. A fish is placed in a small round chamber that is surrounded by vertical black and white stripes. The stripes are rotated around the fish, and the fish responds to the stripes by following them. Visual acuity can be measured by varying the width of the stripes and determining the stripe width at which the fish no longer swims with the stripes. The stripes become so small that they cannot be detected and, thus, the fish does not swim with the stripes. This measure has been used to examine the development of visual acuity (Clark, 1981) and the effects of lighting conditions on visual behavior (Bilotta, Dobis, Googe, Nunley, \& DeLorenzo, 1996).

One downside to the above procedure is that the size of the chamber must be modified with fish of different ages (Bilotta et al., 1996; Clark, 1981). However, our laboratory has developed a procedure that uses a rectangular chamber and moves the stripes back and forth. The striped stimuli are generated by a computer monitor placed on one side of the chamber. The chamber floor is divided into two halves, and the number of crossings per period of time is used as a measure of visual acuity (Nunley \& Bilotta, 1996). The advantage of this procedure over the circular chamber is that one chamber will work across a variety of ages. 


\section{Operant Behavior}

A number of different operant conditioning procedures have been devised for use with zebrafish. These can be divided into appetitive and aversive conditioning techniques. An important factor in the success of these techniques, as discussed above, is to find a behavior that matches zebrafish temperament. For example, one should choose a behavior that requires continuous movement or the opportunity to swim from a restrictive situation. For example, Fetsko, Cohen, Sheffield, and Mote (1996) have been able to train zebrafish to swim into a chamber for a food reinforcement. This is accomplished by presenting a visual stimulus, such as a particular color, in one chamber and a gray stimulus in the other chamber. Clear, Plexiglas doors are opened and the zebrafish are allowed to enter the chambers and receive food reinforcement for entering the chamber with the colored stimulus.

To illustrate the relative ease with which operant conditioning can be used with these subjects to produce reliable results, four adult zebrafish were conditioned to swim through a small opening for a food reward. The apparatus consisted of a 5-gal. glass tank in which the outside walls were covered with an opaque material. A black Plexiglas wall was inserted into the tank to divide the tank into two chambers. The dividing wall contained two rows of three $1^{1 / 4}$-in.-diameter holes. In this experiment, only one hole was used; the others were covered. Positive reinforcement consisted of a small piece of flake fish food delivered on a plastic utensil.

A training session began with a fish placed into the test tank for $10 \mathrm{~min}$ of habituation. Following habitua- tion, the dividing wall was placed into the tank so that the subject was restricted to a small portion of the tank (about $1 / 3$ of the tank). A trial began by removing the plastic cover on the escape hole. The time it took for the subject to swim through the hole was recorded; following this, the subject, who was now in the larger chamber, received a food reward. Once the subject finished the food, the dividing wall was repositioned so that the subject was restricted once again to a small chamber, and the next trial began. Each training session consisted of approximately 21 trials; a subject only participated in one training session per day.

The subject's response latency for each training session was obtained by calculating the median latency on the basis of the total number of trials; using the median eliminated any extreme latencies that were due to the subject being distracted. Figure 1 shows the mean response latency in seconds across training sessions for four fish (data from one fish were only collected for the first four sessions). Zebrafish learned very quickly to swim through the opening for food reinforcement. By the fifth training session, the latency response reached an asymptote; the overall function shown here resembles a typical learning curve. Thus, operant conditioning procedures can be used with zebrafish, and the results are similar to those found in other species.

Aversive conditioning also has been used to train zebrafish. For example, Dill (1974) used an avoidance conditioning paradigm to examine the factors involved in the escape response to a predator. In an avoidance learning study, Gleason, Weber, and Weber (1977) showed

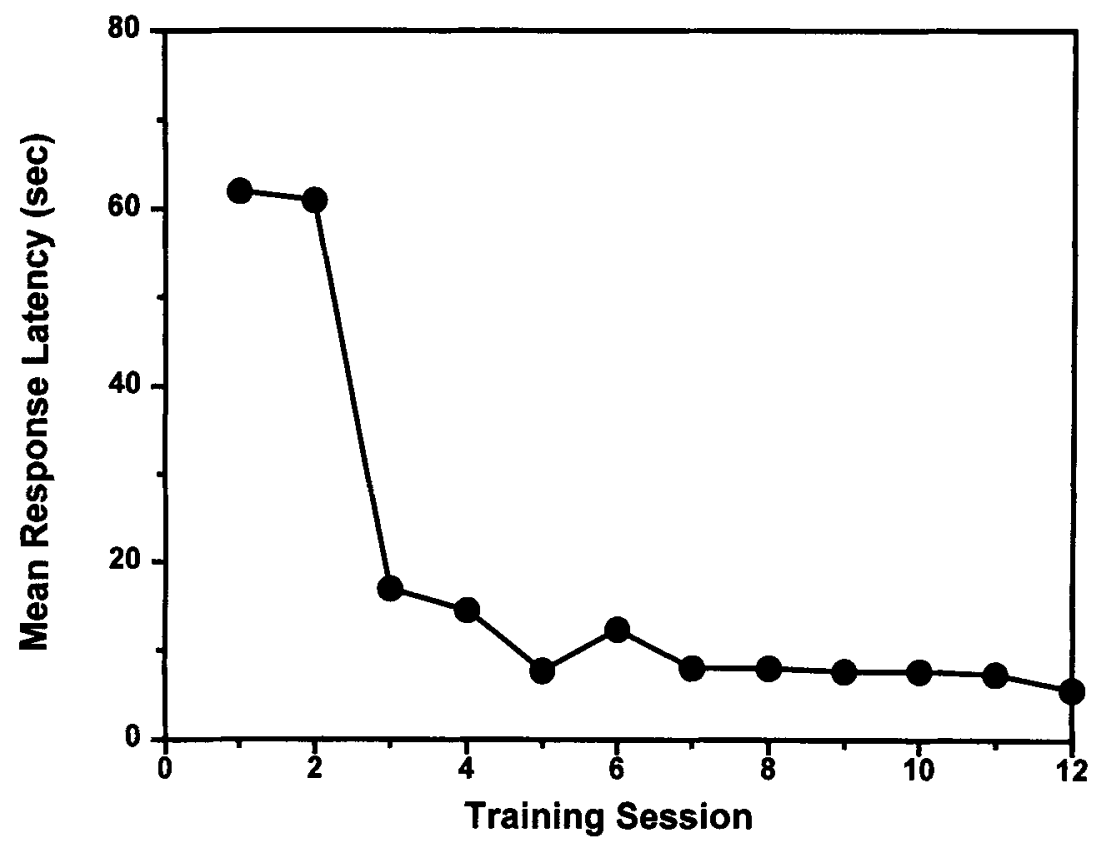

Figure 1. Mean learning curve from four fish. Fish were conditioned to swim through an escape hole for food reinforcement. See the text for details. 
learning curve functions similar to those shown in the present study. Brothers (1996) used avoidance learning to determine the visual ability of the zebrafish under darkadapted conditions. In this study, a two-chamber avoidance tank was used, in which the subjects avoided a shock when they escaped into the chamber after the presentation of a visual stimulus. By varying the intensity of the visual stimulus, Brothers was able to determine the visual thresholds of the zebrafish to stimuli of different wavelengths. Thus, these learning procedures can be used to examine response acquisition and extinction, stimulus generalization and discrimination, and other phenomena associated with an operant conditioning paradigm. Also, once an animal is trained to respond to a particular sensory stimulus, the procedure can be used to examine the subject's sensory abilities by presenting the stimulus at various intensities (see, e.g., Bilotta \& Powers, 1992).

\section{FINAL COMMENTS}

Before setting up the facility, there are several things that need to be considered. The first is whether the facility will meet the appropriate animal care guidelines. If your university has an institutional animal care and use committee, they should be contacted and asked about the regulations and procedures for the university. In addition, all of those involved in developing and maintaining the facility should become familiar with the federal guidelines regarding the use of these vertebrate animals. There are several sources that can be used. For example, the Guide for the Care and Use of Laboratory Animals, published by the National Research Council (1996), is a must, as is the American Psychological Association's (1985) Guidelines for Ethical Conduct in the Care and Use of Animals.

Finally, one also needs to consider what to do with the fish once they have fulfilled their research or demonstration purposes. Zebrafish live about 2 to 3 years, so it is important to have a way of dealing with them within a small facility. In our laboratory, one fairly large tank ( 40 gal.) is used to store the adults for the duration. However, there are other alternatives if the facility cannot accommodate any large tanks. One that our laboratory has used is to find a local elementary school or day care center and give the adult fish to them. Another alternative is euthanasia. This can be done by anesthetic overdose followed by cervical separation. Place the animal in a $0.8-\mathrm{mg} / \mathrm{ml}$ MS-222 solution for several minutes. After this, a sharp pair of scissors can be used to sever the spinal cord, followed by destruction of the brain. The above procedure is an efficient and humane form of euthanasia (Close et al., 1997).

In conclusion, this paper describes a way to develop an animal facility for both classroom laboratories and basic research projects. The system is inexpensive and easy to maintain and can be taken down and set up at any time. Zebrafish are easy to breed and maintain, and there are a variety of procedures that can be used with the zebrafish in behavioral research.

\section{REFERENCES}

Agbayanl, N. (1995). Beam sizes for aquarium stands. Freshwater \& Marine Aquarium, 18, 51-54.

AMERICAN PSYCHOLOGICAL ASSOCIATION (1985). Guidelines for ethical conduct in the care and use of animals [Brochure]. Washington, DC: American Psychological Association.

BARINAGA, M. (1990). Zebrafish swimming into the development mainstream. Science, 250, 34-35.

Bilotta, J., Dobis, W. T., Googe, M. D., Nunley, W. R., \& DeLORENZo, A. S. (1996). The effects of abnormal lighting conditions on zebrafish visual development. Investigative Ophthalmology \& Visual Science, 37(Suppl.), S631.

BilottA, J., \& POWERS, M. K. (1992). Weak stimulus generalization using sinusoidal gratings: A cautionary note in animal psychophysics. Behavior Research Methods, Instruments, \& Computers, 24, 507-510.

BROTHERS, A. I. (1996). An action spectrum of the zebrafish (Brachydanio rerio). Unpublished manuscript, Temple University, Philadelphia.

CLARK, D. T. (1981). Visual responses in developing zebrafish (Brachydanio rerio). Unpublished doctoral dissertation, University of Oregon.

Close, B., Banister, K., Baumans, V., Bernoth, E., Bromage, N., Bunyan, J., Erhardt, W., Flecknell, P., Gregory, N., HackBARTH, H., MORTON, D., \& WARWICK, C. (1997). Recommendations for euthanasia of experimental animals: Part 2. Laboratory Animals, 31, 1-32.

DiLL, L. M. (1974). The escape response of the zebra danio (Brachydanio rerio): I. The stimulus for escape. Animal Behavior, 22, 711-722.

DoBis, W. T., \& Googe, M. D. (1996, April). Effects of $p H$ on the development of the zebrafish. Paper presented at the Sigma Xi Student Research Conference, Bowling Green, KY.

Fetsko, L. A., Cohen, E., Sheffield, J. B., \& Mote, M. I. (1996). Using associative learning to test zebrafish color vision. Society for Neuroscience Abstracts, 22, 886.

Gleason, P. E., Weber, P. G., \& Weber, S. P. (1977). Effect of group size on avoidance learning in zebra fish, Brachydanio rerio (Pisces: Cyprinidae). Animal Learning \& Behavior, 5, 213-216.

Keit H-SPIEgel, P., TABaChnick, B. G., \& SPIEgel, G. B. (1994). When demand exceeds supply: Second-order criteria used by graduate school selection committees. Teaching of Psychology, 21, 79-81.

LaAle, H. W. (1977). The biology and use of zebrafish, Brachydanio rerio in fisheries research. Journal of Fish Biology, 10, 121-173.

MCCANN, L. I., KoEHN, D. J., \& KLINE, N. J. (1971). The effects of body size and body markings on nonpolarized schooling behavior of zebra fish (Brachydanio rerio). Journal of Psychology, 79, 71-75.

MiLls, D. (1993). You and your aquarium. New York: Knopf.

MoOre, C., Hardesty, H. R., Saszik, S., \& BilotTa, J. (1997). Effect of physical space on zebrafish development. Unpublished manuscript, Western Kentucky University, Bowling Green.

National Research Council (1996). Guide for the care and use of laboratory animals. Washington, DC: National Academy Press.

Northmore, D. P. M., VolKmann, F. C., \& YAGER, D. (1978). Vision in fishes: Colour and pattern. In D. J. Mostofsky (Ed.), The behavior of fishes and other aquatic animals (pp. 79-136). New York: Academic Press.

Nunley, W. R., \& BilotTA, J. (1996, April). Development of a new apparatus and procedure to measure contrast sensitivity in zebrafish. Paper presented at the annual meeting of the Kentucky Academy of Science, Frankfort, KY.

Ore, S. G., McElroy, D. M., \& Hoyt, R. D. (1997). Acute low pH impairs chemoreception and feeding performance in larval fathead minnows (Pimephales promelas). Marine \& Freshwater Behavior \& Physiology, 30, 1-17.

PLous, S. (1996). Attitudes toward the use of animals in psychological research and education: Results from a national survey of psychology majors. Psychological Science, 7, 352-358.

Schirone, R. C., \& Gross, L. (1968). Effect of temperature on early embryological development of the zebra fish, Brachydanio rerio. Journal of Experimental Zoology, 169, 43-52.

WeSterfiELD, M. (1994). The zebrafish book (2nd ed.). Eugene: University of Oregon Press. 
APPENDIX

Materials List for a Zebrafish Facility

\begin{tabular}{|c|c|c|}
\hline Equipment Set-up (Required) & & \\
\hline 2 ten-gal. glass aquarium tanks & $\$ 10$ each & $\$ 20.00$ \\
\hline $2100-W$ heaters $(10$-in. Visi-Therm $)$ & $\$ 12$ each & 24.00 \\
\hline 2 aquarium thermometers & $\$ 2.50$ each & 5.00 \\
\hline 2 corner filters (Penn Plax Clear Free) & $\$ 4$ each & 8.00 \\
\hline 3 replacement filter cartridges (Penn Plax, 2 pack) & $\$ 2$ each & 6.00 \\
\hline 1 super battery vacuum & & 18.00 \\
\hline 1 air pump (Whisper 600 ) & & 14.00 \\
\hline 1 air check valve (Aquatronics, 2 pack) & & 3.00 \\
\hline 10 -ft plastic tubing & $\$ 0.10 / \mathrm{ft}$ & 1.00 \\
\hline 2 fish nets (Whisper 3 in.) & $\$ 0.60$ each & 1.20 \\
\hline Instant Ocean Salt (25-gal. mix) & & 9.00 \\
\hline Flake food (Tetramin for Tropical Fish, $3.53 \mathrm{oz})$. & & 6.00 \\
\hline 12 adult zebrafish & $\$ 2.00$ each & 24.00 \\
\hline Total for set-up & & $\$ 139.20$ \\
\hline Water Conditioning (Optional) & & \\
\hline Tap water deionizer (Aquarium Pharmaceuticals) & & $\$ 26.00$ \\
\hline 2 deionizer refill cartridges & $\$ 14.00$ each & 28.00 \\
\hline Chlorine neutralizer (Kordon NovAqua, 16 oz.) & & 5.00 \\
\hline pH stabilizer (Wardley Bullseye $7.0 \mathrm{pH}, 16 \mathrm{oz}$.) & & 9.00 \\
\hline $\mathrm{pH}$ increaser or decreaser (Jungle, $16 \mathrm{oz}$. ) & & 5.00 \\
\hline Egg fungus treatment (Methylblu, $1 \mathrm{oz}$.) & & 4.00 \\
\hline Total for water conditioning & & $\$ 77.00$ \\
\hline Water Testing (Required) & & \\
\hline Water hardness test (Aquarium Pharmaceuticals GH \& KH Kit) & & 5.00 \\
\hline $\mathrm{pH}$ freshwater test (Aquarium Pharmaceuticals) & & 3.00 \\
\hline Freshwater ammonia tester (Aquarium Pharmaceuticals) & & 5.00 \\
\hline Total for water testing & & $\$ 13.00$ \\
\hline Breeding Set-up (Required) & & \\
\hline Minnow net $(1 / 8$-in. mesh $)$ & & $\$ 5.00$ \\
\hline 2 brine shrimp hatcheries & $\$ 15.00$ each & 30.00 \\
\hline Brine shrimp eggs (OSI, 15 oz.) & & 35.00 \\
\hline 2 fry food solution (Liquifry for egglayers, $19.8 \mathrm{ml}$ ) & $\$ 2.00$ each & 4.00 \\
\hline Plastic freezer containers & $\$ 5.00$ pack & 5.00 \\
\hline Total for breeding set-up & & $\$ 79.00$ \\
\hline Developmental Staging (optional but suggested) & & \\
\hline Stereoscope (Edmund Scientific; A52,363; A34,746) & & $\$ 325-\$ 600$ \\
\hline Totals & & \\
\hline Required & & $\$ 231.20$ \\
\hline Optional & & 77.00 \\
\hline Optional but suggested & & 600.00 \\
\hline Total & & $\$ 908.20$ \\
\hline
\end{tabular}

(Manuscript received June 12, 1997;

revision accepted for publication February 3, 1998.) 